\title{
Gender differences in a Type 2 (non-insulin-dependent) diabetic population with respect to apolipoprotein $E$ phenotype frequencies
}

\author{
M. Boemi ${ }^{1}$, R. W. James ${ }^{2}$, F. Romagnoli ${ }^{1}$, P. Gerber ${ }^{2}$ D.Pometta $^{2}$ and P. Fumelli $^{1}$ \\ ${ }^{1}$ Division of Diabetology, INRCA, Ancona, Italy, and \\ ${ }^{2}$ Division of Diabetology, University Hospital, Geneva, Switzerland
}

\begin{abstract}
Summary. Apolipoprotein E polymorphism was examined in an Italian population of Type 2 (non-insulin-dependent) diabetic patients. There were significant differences $(p<0.05)$ in allele frequencies between male and female patients due to an under-representation of the E4 allele in the female group. No differences in allele frequencies were noted when non-diabetic male and female control subjects were compared. Both control groups exhibited similar allele distributions to that of male diabetic patients, but were significantly different $(p<0.05)$ from female diabetic patients. A closer examination of the female diabetic population revealed that under-representation of the $\mathrm{E} 4$ allele was princi-
\end{abstract}

pally confined to patients aged 60 years or older. This subgroup showed a significantly different $(p<0.05)$ allele frequency profile from control subjects (both men and women) and diabetic men, whereas this was not observed in the younger diabetic women ( $\leq 59$ years). The results are consistent with the suggestion that the E4 allele may be a particular risk factor for female diabetic patients.

Key words: Type 2 (non-insulin-dependent) diabetes mellitus, apo E polymorphism, plasma lipids, lipoproteins, cardiovascular risk factor.
Cardiovascular disease is one of the principal complications of diabetes mellitus and a major cause of morbidity and mortality [1]. Femalle diabetic patients are notably at increased risk as their natural protection from atherosclerotic disease is compromised by the diabetic condition $[2,3]$. Lipid abnormalities are a common occurrence in poorly-controlled diabetic subjects $[1,4-6]$. It is logical to consider them as a primary source of subsequent cardiovascular complications given their status as leading risk factors in the non-diabetic population.

Studies over the last decade [7-10] have clarified the importance of apolipoprotein (apo) E to blood lipid/lipoprotein metabolism. It mediates hepatic elimination of potentially atherogenic remnant particles generated by the lipolysis of triglyceride-rich lipoproteins (chylomicrons, VLDL). Of equal clinical significance are the consequences of apo E polymorphism. Three major isoforms are recognised: apo E3, the ancestral protein, and two mutants, apo E2 and apo E4, derived from the former by point mutations [11]. Both mutations can pathologically influence blood levels of triglycerides and cholesterol $[7,8,12]$. Indeed, for a single gene locus, apo E polymorphism would appear to have an astonishingly important effect on plasma cholesterol concentrations of the general population, being responsible for some $16 \%$ of genetic variation ( $8 \%$ of overall variation $[13,14]$ ).
Given the propensity of diabetic patients to develop lipid disorders, notably hypertriglyceridaemia, an obvious consideration is whether apo E polymorphism is a particular risk factor in this population. Only a limited number of studies have been performed concerning this topic [15-19] and have tended to use small groups of patients. Our intention was to address the question in a large, clinically well-documented population. During the course of the study, we observed male-female differences in apo E polymorphism of the diabetic populations. This is the first occasion that such gender differences have been noted and could have important implications for apo E polymorphism as a risk factor in female diabetic patients.

\section{Subjects and methods}

\section{Study populations}

Diabetic patients were recruited from those consecutively attending the Diabetes Centre of Ancona Hospital for their routine visits (every 1-2 months). A total of 517 patients were enrolled, of which 81 were Type 1 (insulin-dependent) diabetic subjects. These subjects were excluded from the present study, leaving 436 Type 2 (non-insulin-dependent) diabetic patients, 211 men and 225 women. A total of 73 patients ( 23 men, 50 women) were taking lipid lowering medi- 
Table 1. Clinical parameters of male and female Type 2 diabetic patients

\begin{tabular}{lcc}
\hline Parameter & Male & Female \\
$n$ & 215 & 225 \\
\hline Age (years) & $62.9 \pm 11.5$ & $65.0 \pm 10.3^{\mathrm{a}}$ \\
$\mathrm{HbA} \mathrm{I}_{\mathrm{IC}}(\%)$ & $7.4 \pm 1.6$ & $7.8 \pm 1.6^{\mathrm{a}}$ \\
Duration of diabetes (years) & $12.4 \pm 8.5$ & $13.8 \pm 8.3$ \\
BMI (kg/m $\left.{ }^{2}\right)$ & $26.8 \pm 3.5$ & $27.3 \pm 4.3$ \\
Cholesterol (mmol/l) & $5.42 \pm 1.02$ & $5.88 \pm 1.20^{\mathrm{a}}$ \\
Triglycerides (mmol/l) & $1.85 \pm 1.22$ & $1.82 \pm 1.45$ \\
HDL-cholesterol (mmol/l) & $1.04 \pm 0.26$ & $1.17 \pm 0.30^{\mathrm{a}}$ \\
Apo A-I (g/l) & $1.26 \pm 0.25$ & $1.36 \pm 0.24^{\mathrm{a}}$ \\
Apo B (g/l) & $0.94 \pm 0.29$ & $1.00 \pm 0.30^{\mathrm{b}}$ \\
\hline
\end{tabular}

Mean $( \pm S D)$ for male and female diabetic patients. Lipid values refer to plasma concentrations. Statistical comparisons were performed with the non-paired $t$-test. ${ }^{a} p<0.01,{ }^{b} p<0.03$ vs male patients

cation (which was not discontinued) and 123 patients (52 men, 71 women) were receiving insulin. Diagnosis of Type 2 diabetes was based on World Health Organisation diagnostic criteria, supplemented where necessary by measurements of plasma and urinary C-peptide.

Non-diabetic control subjects were recruited from those attending the blood donor centre in Ancona. A total of 365 subjects were enlisted, $296 \mathrm{men}$ ( $43.2 \pm 10.6$ years; range $20-64$ years) and 69 women ( $42.0 \pm 14.3$ years; range $21-64$ years) which is a representative ratio of subjects attending the centre.

Fasting blood samples were centrifuged to obtain plasma which was rapidly frozen and stored at $-70^{\circ} \mathrm{C}$. The frozen samples were transferred on dry ice to Geneva every $1-2$ months for apo E phenotyping and measurement of blood lipid and apolipoprotein levels.

\section{Apolipoprotein E phenotyping}

Apo E was phenotyped using a modified version of the procedure of Menzel et al. [20]. The modifications [21] entailed the use of whole plasma, instead of very low density lipoprotein, as the source of apo
$\mathrm{E}$, and visualisation of apo $\mathrm{E}$ using a high affinity, pan apo $\mathrm{E}$ monoclonal antibody produced in our laboratory. The procedure facilitates differentiation of sialylated and non-sialylated forms of apo $\mathrm{E}$ e.g. apo E3 from sialylated apo E4 and apo E2 from sialylated E3, as the non-sialylated forms focus in front of the sialylated derivatives [20].

\section{Lipid and apolipoprotein assays}

Plasma cholesterol, triglycerides and HDL cholesterol (after precipitation of lower density lipoproteins with phosphotungstate) were assayed enzymatically and apos A-I and B by electroimmunoassay, as described previously [22]. LDL-cholesterol was calculated as (total cholesterol - HDL-cholesterol - (triglycerides/5)) for triglycerides less than $5.0 \mathrm{mmol} /$. Five diabetic patients (three with $\mathrm{E} 3 / 3$, one with $\mathrm{E} 3 / 2$ and one with $\mathrm{E} / 3$ ) were excluded from this analysis due to triglyceride levels above $5.0 \mathrm{mmol} / \mathrm{h}$.

\section{Statistical analysis}

Statistical analysis of phenotype distributions was performed with the chi-square test. Other comparisons were made using the unpaired Student's $t$-test.

\section{Results}

Various clinical parameters of the male and female, Type 2 diabetic populations are shown in Table 1 . Both populations had good metabolic control as they were within the upper normal range (limit $8.1 \%$ ) for $\mathrm{HbA}_{1 \mathrm{C}}$ concentrations, although females had significantly higher levels than men. The two groups did not show significant differences with respect to BMI or duration of diabetes. As regards lipid parameters, triglyceride levels were similar in both groups, whereas plasma cholesterol concentrations were significantly lower in males.

Table 2. Lipid and lipoprotein concentrations in diabetic patients as a function of apo E polymorphism

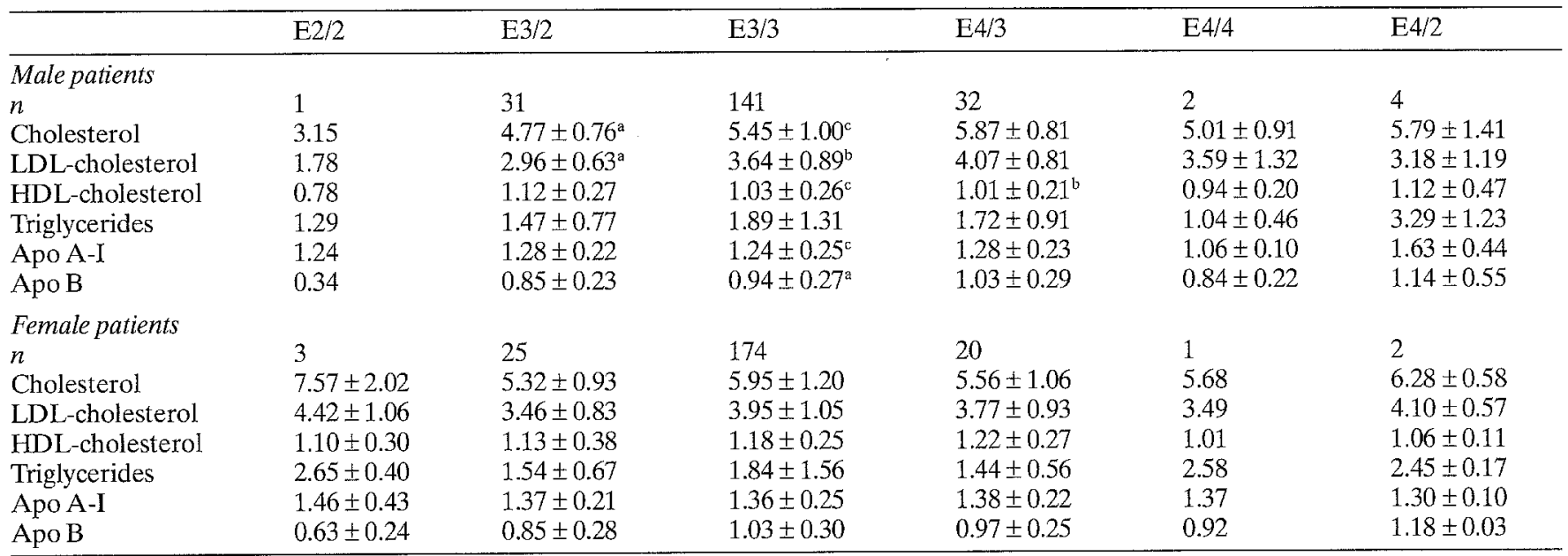

Plasma concentrations (mean $\pm \mathrm{SD}$ ) of lipids (mmol/l) and apolipoproteins $(\mathrm{g} / \mathrm{l})$ in diabetic patients as a function of apo E polymorphism. Statistical comparisons were made only for phenotypes E3/2, E3/3 and E4/3 using the unpaired Student's $t$-test. ${ }^{a} p<0.02$;

${ }^{\mathrm{b}} p<0.005 ;{ }^{\mathrm{c}} p<0.001$ vs corresponding phenotype of female pa- tients. Other comparisons were not significant at $p \leq 0.05$. For LDLcholesterol of male patients, $n=139$ for $E 3 / 3$ and 30 for $E 3 / 2$; for LDL-cholesterol of female patients, $n=173$ for E3/3 and $n=19$ for $\mathrm{E} 4 / 3$ 
Table 3. Apo E phenotype frequencies in male and female Type 2 diabetic and non-diabetic populations

\begin{tabular}{|c|c|c|c|c|}
\hline \multirow[t]{3}{*}{ Phenotype } & \multicolumn{4}{|c|}{ Relative frequency } \\
\hline & \multicolumn{2}{|l|}{ Men } & \multicolumn{2}{|l|}{ Women } \\
\hline & $\mathrm{D}$ & $\mathrm{C}$ & $\mathrm{D}$ & $\mathrm{C}$ \\
\hline$n$ & 211 & 296 & 225 & 69 \\
\hline$\overline{2 / 2}$ & $0.005(1)$ & $0.010(3)$ & $0.013(3)$ & $0(0)$ \\
\hline $3 / 2$ & $0.147(31)$ & $0.115(34)$ & $0.111(25)$ & $0.130(9)$ \\
\hline $3 / 3$ & $0.668(141)$ & $0.713(211)$ & $0.773(174)$ & $0.667(46)$ \\
\hline $4 / 3$ & $0.152(32)$ & $0.135(40)$ & $0.089(20)$ & $0.160(11)$ \\
\hline $4 / 4$ & $0.009(2)$ & $0.017(5)$ & $0.004(1)$ & $0.029(2)$ \\
\hline $4 / 2$ & $0.019(4)$ & $0.010(3)$ & $0.009(2)$ & $0.014(1)$ \\
\hline
\end{tabular}

Relative phenotypic frequencies for diabetic (D) and control (C) subjects were calculated from the absolute frequency distributions which are the values given in parentheses

Table 4. Allele frequencies of diabetic and non-diabetic male and female subjects

\begin{tabular}{llllll}
\hline Allele & \multicolumn{3}{l}{ Relative frequency } & & \\
\cline { 2 - 3 } & \multicolumn{2}{l}{ Men } & & Women & \\
\cline { 2 - 3 } \cline { 5 - 6 } & $\mathrm{D}$ & $\mathrm{C}$ & & $\mathrm{D}$ & $\mathrm{C}$ \\
\hline E2 & 0.088 & 0.073 & & 0.073 & 0.072 \\
E3 & 0.817 & 0.838 & & 0.873 & 0.812 \\
E4 & 0.095 & 0.089 & & 0.053 & 0.116 \\
\hline
\end{tabular}

Relative allele frequencies for the populations were calculated from the phenotypes given in Table 3

Table 2 gives the lipid and apolipoprotein levels in the diabetic populations as a function of apo $\mathrm{E}$ phenotype. Statistical comparisons between male and female patients were limited to E3/2, E3/3 and E4/3 phenotypes. Significantly higher plasma and LDL-cholesterol concentrations were noted in diabetic women with E3/2 or E3/3 phenotypes, but not those with the E4/3 phenotype. Similar results were obtained when subjects taking lipid lowering medication were eliminated from the subgroups. When comparisons were made within genders, women had significantly lower total and LDL cholesterol levels in the E3/2 subgroup as compared to E3/3 and E4/3 phenotypes; the latter subgroups did not differ significantly. In men, E3/2 phenotypes had significantly lower levels of these lipids than E3/3 and E4/3 phenotypes; the E3/3 subgroup was also significantly lower than E4/3 subgroup for these parameters. There were no significant differences in triglyceride levels.

The apo E phenotypic and allele frequencies of the male and female populations are shown in Tables 3 and 4 . When the distribution for the major apo $\mathrm{E}$ phenotypes (E3/2, E3/3 and E4/3) were compared, they were found to be significantly different between the two populations $\left(\chi^{2}=6.35, p<0.05\right)$. This difference was also evident when allele frequencies were compared $\left(\chi^{2}=6.46, p<0.05\right)$.

Closer examination of the apo $\mathrm{E}$ frequency distribution indicated that gender differences resided mainly within the E4 isoform: the relative frequency of this allele in the female population was one-half that observed in the male population. The relative frequencies of the other apo $\mathrm{E}$ mutant, E2, were similar in the two groups.
To determine whether these observations reflected inherent differences between Italian male and female populations, apo $\mathrm{E}$ polymorphism in non-diabetic control populations was analysed. As shown in Table 4, no significant, gender-based differences in allele frequencies were evident $\left(\chi^{2}=0.9\right)$. Neither the non-diabetic nor the diabetic men demonstrated differences in allele frequencies (see Table $4 ; \chi^{2}=0.9$ ). There were, however, significant differences $(p<0.05)$ between female non-diabetic and diabetic subjects. Correspondingly, the combined male/female control population was found to be in HardyWeinberg equilibrium with the male diabetic population, but not with the female diabetic population $(p<0.05)$.

In comparison to other apo $\mathrm{E}$ isoforms, it has been reported that the E4 phenotype is associated with cardiovascular disease at a significantly younger age $[23,24]$. Thus, subjects possessing the E4 isoform may potentially be lost earlier from such populations. We analysed whether the E4 allele frequency differed between younger ( $<60$ years) and older ( $\geq 60$ years) diabetic patients. Neither of the male diabetic subgroups showed significant differences $\left(\chi^{2}=1.66\right.$ and 0.17 , respectively for younger $(n=74)$ and older $(n=137)$ patients) in allele frequency when compared to non-diabetic control subjects. In contrast, older female patients $(n=165)$ had a significantly different allele distribution from that of female control subjects $\left(\chi^{2}=6.96, p<0.05\right)$. This was again attributable to a reduced E4 allele frequency ( $4.8 \%$ vs $11.6 \%)$. The apo E allele frequency of younger diabetic women $(n=60)$ did not differ significantly from that of control subjects $\left(\chi^{2}=1.94\right)$.

\section{Discussion}

This is the first report of a gender difference in the apo $\mathrm{E}$ allelic distribution profile of a diabetic population. It is due to a lower E4 allele representation in diabetic women, a group where the natural female resistance to cardiovascular disease is severely compromised. In addition, there may be an age factor, as diabetic women over 60 years of age had a significantly different frequency from nondiabetic control subjects, whilst this was not the case for younger female diabetic patients. In contrast to these observations in diabetic women, apo E phenotype/allele frequencies were not significantly different between male diabetic and control subjects.

Although we offer no hard data, it appears logical to link our observations to cardiovascular disease, given the role of apo $\mathrm{E}$ in lipid metabolism. As mentioned earlier, apo E4 is associated with pathological modifications of blood lipid levels, notably increases in plasma cholesterol concentrations [7-10] and deleterious influences on triglyceride and HDL cholesterol levels [25]. This may be reflected in the tendency for E4 subjects to develop coronary heart disease at a younger age, at least in men $[23,24]$. Such results have led Davignon et al. [7] to suggest that age may have a major influence on the impact of apo $E$ on cardiovascular disease. These same authors also concluded that the $\mathrm{E} 4$ allele in particular may confer a genetic predisposition to atherosclerotic disease in subjects 
placed in an unfavourable environment. This eventuality, taken together with our observations that the female diabetic group, particularly older patients, has a reduced $\mathrm{E} 4$ allele frequency, raises some interesting questions. Although the underlying mechanisms have yet to be elucidated, it is well documented $[2,3]$ that diabetes particularly augments the female susceptibility to atherosclerotic disease. Could the diabetic condition provide an unfavourable environment wherein the $\mathrm{E} 4$ isoform has a more deleterious influence in female patients? If so, a corollary to this question is why the male diabetic population does not also show a reduced E4 allele representation. Comparisons of male and female diabetic patients according to phenotype offered no indications as to the causes of the gender differences in the E4 allele frequency. Neither cholesterol nor triglycerides were significantly different between patients with the E4/3 phenotype (even when patients taking lipid lowering medication were eliminated from the subgroups). Other comparisons, including $\mathrm{HbA}_{1 \mathrm{C}}$, BMI and duration of diabetes, also failed to reveal differences between male and female patients with the $\mathrm{E} 4$ isoform. However, it is difficult to extrapolate from such comparisons as they will be influenced by the apparent preferential loss of female patients with the $\mathrm{E} 4$ isoform.

The majority of studies performed to date has failed to reveal gender differences in apo $\mathrm{E}$ polymorphism $[13,20$, $23,26,27]$, although a study in octogenarians suggested under-representation of the E4 isoform notably in women [28]. Other reports suggest that apo E isomers have consistent effects on plasma cholesterol levels irrespective of the population source or the average cholesterol concentration of that population [7]. However, Xhignesse et al. [27], comparing non-diabetic male and female populations, have concluded that there may be gender differences in the degree to which apo E polymorphism affects plasma lipid levels, the influence of the E4 allele on LDL metabolism being of greater magnitude in women. Also, in a report which appeared after completion of the present investigation, Laakso et al. [29] concluded that the apo E4 isoform was an important risk indicator for coronary heart disease in non-insulin-dependent diabetes (although they were unable to offer an explanation for the mechanism underlying the effect). Unfortunately, the study only considered male patients. In the light of these reports, our observations are consistent with the proposal that the combination of diabetes and the E4 allele could confer a particular disadvantage on the female population.

There is at present no obvious explanation as to why female diabetic patients possessing the $\mathrm{E} 4$ allele should be at a disadvantage in comparison to their male diabetic counterparts, but it may have a bearing on their greatly increased risk of developing cardiovascular disease, for which an explanation is similarly lacking. The small number of studies of apo E polymorphism in diabetic populations has revealed no gender differences, although it should be emphasised that females were not specifically targeted in these studies. Further studies are merited to determine whether our observations can be extrapolated to other populations, or are specific to the Italian population, and to test our suggestion that the E4 allele may be a particular risk factor in the female diabetic population.
Acknowledgements. The authors are very grateful for the technical expertise of Ms B.Wojtek, M.-C. Brulhart, F.Ruinard and Dr. R. Ricciotti. The study was supported by grants from the Fonds National de la Recherche Scientifique (No. 32-30 782.91) and from the Fondation suisse du Diabète.

\section{References}

1. Pyörälä K, Laakso M, Uusitupa M (1987) Diabetes and atherosclerosis: an epidemiological view. Diab Metab Rev 3: 463-524

2. Barrett-Connor E, Wingard DL (1983) Sex differential in ischaemic heart disease mortality in diabetics: a prospective population-based study. Am J Epidemiol 118: 489-496

3. Krowlewski AS, Warram JH, Valsania P, Martin BC, Laffel LMB, Christlieb AR (1991) Evolving natural history of coronary artery disease in diabetes mellitus. Am J Med 90 [Suppl 2A]: $56 \mathrm{~S}-61 \mathrm{~S}$

4. Barrett-Connor E, Grundy S, Holdbrook MJ (1982) Plasma lipids and diabetes mellitus in an adult community. Am J Epidemiol 115: 657-663

5. Assmann G, Schulte H (1987) The prospective cardiovascular Münster (PROCAM) study: prevalence of hyperlipidemia in persons with hypertension and/or diabetes mellitus and the relationship to coronary heart disease. Am Heart J 116: 1713-1724

6. Stern MP, Patterson JK, Haffner SM, Hazuda HP, Mitchell BD (1989) Lack of awareness and treatment of hyperlipidemia in type II diabetes in a community survey. JAMA 262: 360-364

7. Davignon J, Gregg RE, Sing CF (1988) Apolipoprotein E polymorphism and atherosclerosis. Arteriosclerosis $8: 1-21$

8. Utermann G (1987) Apolipoprotein E polymorphism in health and disease. Am Heart J 113: 433-440

9. Mahley RW (1988) Apolipoprotein E: cholesterol transport protein with expanding role in cell biology. Science 240: 622 630

10. Breslow JL (1985) Human apolipoprotein molecular biology and genetic variation. Annu Rev Biochem 54: 699-727

11. Zannis VI, Breslow JL, Utermann G et al. (1982) Proposed nomenclature of apo E isoproteins, apo E genotypes and phenotypes. J Lipid Res 23: 911-914

12. Brewer HB, Zech LA, Gregg RE, Schwartz D, Schaefer EJ (1983) Type III hyperlipoproteinemia: diagnosis, molecular defects, pathology and treatment. Ann Int Med 98:623-640

13. Boerwinkle E, Visvikis S, Welsh D, Steinmetz MS, Hanash SM, Sing CF (1987) The use of measured genotype information in the analysis of quantitative phenotypes in man: II. The role of the apolipoprotein $\mathrm{E}$ polymorphism in determining levels, variability and co-variability of cholesterol, beta-lipoprotein and triglycerides in a sample of unrelated individuals. Am J Med Genet 27: 567-582

14. Boerwinkle E, Utermann G (1987) Simultaneous effects of the apolipoprotein $\mathrm{E}$ polymorphism on apolipoprotein $\mathrm{E}$, apolipoprotein B and cholesterol metabolism. Am J Hum Genet 42: 104-112

15. Eto E, Watanabe K, Iwashima Y, Morikawa A et al. (1986) Apolipoprotein $\mathrm{E}$ polymorphism and hyperlipemia in type II diabetics. Diabetes 35: 1374-1382

16. James RW, Voliotis C, Grab B, Pometta D (1987) Phénotypes de l'apoprotéine $\mathrm{E}$ (apo $\mathrm{E}$ ) et lipides sériques des diabetiques. Schweiz Med Wschr 117: 2021-2023

17. Imari Y, Koga S, Ibayashi H (1988) Phenotype of apolipoprotein $E$ and abnormalities in lipid metabolism in patients with non-insulin dependent diabetes mellitus. Metabolism 37: 1134-1138

18. Winocour PH, Tetlow L, Durrington PN, Ishola M, Hillier V, Anderson VD (1989) Apolipoprotein E polymorphism in insulin treated diabetes mellitus. Atherosclerosis 75: 167-173

19. Shriver MD, Boerwinkle E, Hewett-Emmett D, Hanis CL (1991) Frequency and effects of apolipoprotein E polymorphism in Mexican-American NIDDM subjects. Diabetes 40:334-337 
20. Menzel HJ, Kladetzky RG, Assmann G (1983) Apolipoprotein E polymorphism and coronary artery disease. Arteriosclerosis 3 : 310-315

21. Borghini I, James RW, Pometta D (1989) Maladie des remnants (remnants disease) associée à l'apoprotéine E1; importance clinique des phénotypes de l'apoprotéine E (apo E). Schweiz Med Wschr 119: 1821-1824

22. James RW, Pometta D (1990) Differences in lipoprotein subfraction composition and distribution between type I diabetic men and control subjects. Diabetes 39: 1158-1164

23. Cumming AM, Robertson F (1984) Polymorphism at the apo E locus in relation to the risk of coronary disease. Clin Genet 25 : $310-313$

24. Lenzen HJ, Assmann G, Buchwalsky R, Schulte H (1986) Association of apolipoprotein $\mathrm{E}$ polymorphism, low density lipoprotein cholesterol and coronary artery disease. Clin Chem 32: 778781

25. Dallongeville J, Lussier-Cacan S, Davignon J (1992) Modulation of plasma triglyceride levels by apo E phenotype: a meta-analysis. J Lipid Res 33: 447-454

26. Ordovas JM, Litwack-Klein L, Wilson PWF, Schaefer MM, Schaefer EJ (1987) Apolipoprotein E isoform phenotyping methodology and population frequency with identification of apo E1 and apo E5 isoforms. J Lipid Res 28:371-380
27. Xhignesse M, Lussier-Cacan S, Sing CF, Kessing AM, Davignon $J$ (1991) Influences of common variants of apolipoprotein $E$ on measures of lipid metabolism in a sample selected for health. Arterioscler and Thrombosis 11: 1100-1109

28. Davignon J, Sing CF, Lussier-Cacan S, Nestruck AC, Bouthillier $D$ (1986) Importance of apolipoprotein $\mathrm{E}$ polymorphism in determining plasma lipid levels and atherosclerosis. In: Fidge NH, Nestel PJ (eds) A therosclerosis VII. Excerpta Medica, Amsterdam, pp 171-175

29. Laakso M, Kesäniemi A, Kervinen K, Jauhiainen M, Pyörälä K (1991) Relation of coronary heart disease and apolipoprotein $\mathrm{E}$ phenotype in patients with non-insulin dependent diabetes. $\mathrm{Br}$ Med J 303: 1159-1162

Received: 24 June 1992

and in revised form: 13 October 1992

Dr. R. W.James

Division of Diabetology

Department of Medicine

University Hospital

$\mathrm{CH}-1211$ Geneva 14

Switzerland 